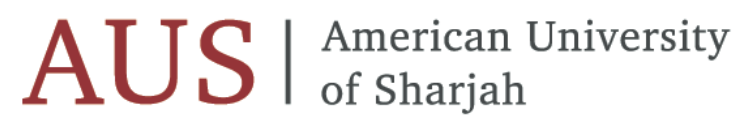

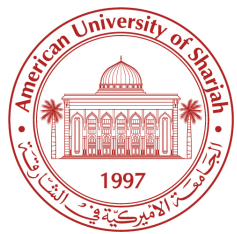

SCHOOL OF BUSINESS AND MANAGEMENT WORKING PAPER SERIES

SBMWPS: 07-05/2013

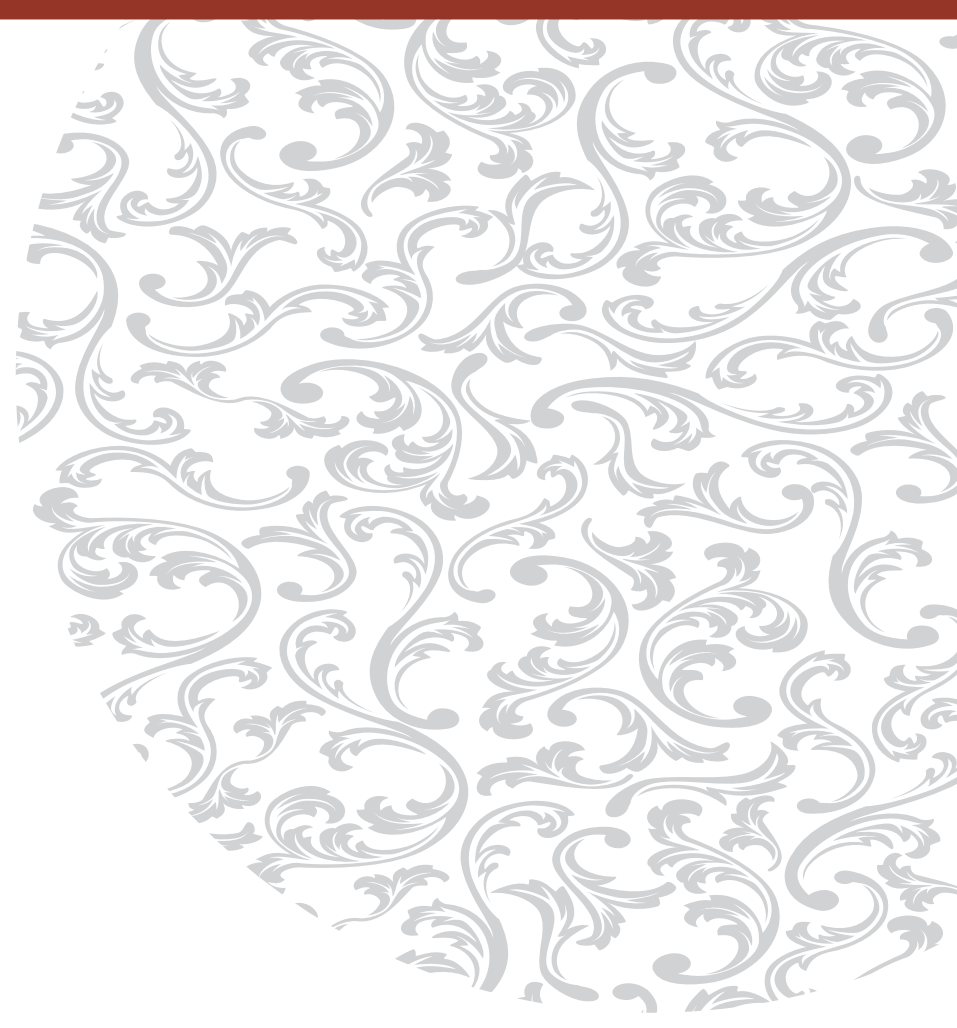

Structural Change in MENA

Remittance Flows

George S. Naufal

Ismail H. Genc 
Working Paper 07-05/2013

School of Business \& Management

Working Paper Series (SBM WPS)

\title{
Structural Change in MENA Remittance Flows
}

\author{
George S. Naufal \\ AUS
}

\section{Ismail H. Genc}

AUS

The views expressed in papers published in our series are those of the author(s) and do not necessarily represent those of any department at SBM, the SBM itself, the American University of Sharjah (AUS) and/or any of their affiliates. Additionally, all papers in the series are made available on an "as is" basis without warranties of any kind. We, that is, the relevant department at SBM, SBM, AUS and/or any of the affiliates, hereby expressly disclaim any warranties of any kind, whether expressed or implied, including without limitation, the warranties of noninfringement, merchantability, and fitness for a particular purpose. Furthermore, we offer no warranties, expressed or implied, regarding the accuracy, sufficiency or suitability of the material found in the published papers. The users have the sole responsibility for inspecting and testing all content to their satisfaction before using them. 


\section{Structural Change in MENA Remittance Flows}

George S. NAUFAL and Ismail H. GENC

School of Business and Management American University of Sharjah

PO BOX 26666, Sharjah UAE 


\begin{abstract}
After independence, the GCC countries relied heavily on foreign workers from fellow Arabs countries. Thus, remittances flowed from GCC to other countries in MENA. In the 1980s-1990s labor source switched to South Asia, which we econometrically verify. This deprived several MENA labor exporters of large sums of foreign exchange, adding significant economic, social and political hardships on non-GCC MENA countries.
\end{abstract}

JEL classifications: F16, F22, F24, C22

Key words: Migration, Remittances, Unit roots, Structural break, the Gulf Cooperation Council (GCC), Middle East and North Africa (MENA) 


\section{Introduction and Motivation}

The Gulf Cooperation Council (GCC) countries have been one of the destination countries for millions of expatriates for more than four decades now. ${ }^{1}$ Suffering from a small and inexperienced local population but enjoying some of the largest endowments of natural resources in the world (oil and gas), the Gulf countries have turned to foreign labor to satisfy labor shortages that came as a result of massive development projects. The flow of foreign workers has been so large that the Gulf region is known as the third most important labor-receiving region in the world only after North America and Europe (Adams 2009).

The source countries of labor to the Gulf region, although very diverse, are not random but instead reflect labor policies in GCC. Non-GCC Arab workers used to be the first choice for employment in the 1970s and mid-1980s due to the proximity and similarity in culture, religion and language. However, GCC systematically replaced Arab expatriates with non-Arab foreigners mainly from South Asia as early as late 1980s (Birks, Seccombe and Sinclair 1988; Russell 1989; Khadria 2008; Naufal 2011; and Naufal and Genc 2012). ${ }^{2}$ Further, the literature on GCC migration has documented a distinct shift in the nationality of foreign workers right around Operation Desert Storm (1990-1991).

The systematic change in the source of foreign workers was reflected by a shift in the destination of remittance outflows from the Gulf. Figure 1 shows that mean remittance outflows and inflows in the Middle East and North Africa (MENA) region tracked each other closely until 1990 where outflows maintained their upward trend while remittance inflows declined until 2000 before reverting to an upward trend. Figure 1 basically suggests that money outflows from GCC used to return back to non-GCC MENA countries until 1990 when remittance outflows remained

\footnotetext{
${ }^{1}$ The GCC countries are Bahrain, Kuwait, Oman, Qatar, Saudi Arabia (KSA) and United Arab Emirates (UAE).

${ }^{2}$ Choucri (1986) observes a much earlier shift as early as in 1975.
} 
strong, but now have new destination countries such as India, Bangladesh, Pakistan and the Philippines, while depriving countries such as Egypt of a significant source of income (Naufal, 2011).

\section{[INSERT FIGURE 1 ABOUT HERE]}

This paper builds on Figure 1 and examines the time series characteristics of remittance inflows and outflows in the MENA region. Specifically we test the existence of structural breaks in both data series. Ignoring structural breaks seriously affects interpretation of economic relationships distorting economic forecasts and policy recommendations. More importantly, if there are, in fact, structural breaks in remittance data, labor exporting countries should have taken precautions in due time to eliminate resultant economic hardships, with likely significant social and poitical implications. Also, to our knowledge this is the first paper which investigates the structural breaks in remiitances for the region.

\section{Data and Methodology}

Data for annual remittance flows (1970-2010) come from World Development Indicators Online Databases. Remittances could be either trend stationary or difference stationary. Unit root tests are the standard procedure to examine the time series properties of data. The Augmented Dickey Fuller (ADF) tests are usually employed for that purpose. A known weakness of the DickeyFuller test is its potential confusion of structural breaks in data as proof of nonstationarity. The Zivot Andrews (ZA) test allows investigating the presence of unit roots with the possibility of one structural break, which may be in the intercept, in the slope or trend, or both. ${ }^{3}$

\footnotetext{
${ }^{3}$ For details of the equations to estimate, see Zivot and Andrews (1992) with an application on the GCC countries, see Genc, Darayseh and AbuAl-Foul (2011).
} 
A known weakness of the ZA test is its inability to deal with multiple structural breaks in the series. To address this issue, we adopt Clemente, Montanes, and Reyes (1998) (CMR) test. CMR's null hypothesis is a unit root with two structural breaks, whereas its alternative hypothesis claims that the series is stationary with two structural breaks. The test equations are also based on specifications similar to ZA. CMR investigates data for a sudden change in the mean of the series, the additive outliers model (AO), or alternatively for a smooth transition over time, the innovational outliers (IO) model, which allows for a gradual shift in the mean of the series. In practice, if the estimates of a method such as CMR provide evidence of a significant structural break, results based on a method such as ADF should be interpreted as evidence of misspecification (Baum 2005). Comparison to a method allowing only one structural break should also be considered in the same sense. In other words, one should check for the largest number of breaks in data before trying more restrictive formats to avoid the bias toward the failure to reject the non-stationarity assumption arising from the existence of structural breaks. ${ }^{4,5}$

\section{[INSERT TABLE 1 ABOUT HERE]}

\section{Discussion of Results}

The results of the CMR tests are shown in Table 1. Both remittance inflows and outflows are non-stationary. Thus, per our earlier discussion, remittance data are difference stationary. That is, any shock hitting these variables would last forever without reverting back to the preshock means. This is the evidence of a permanent shift in levels and indicative of a directional

\footnotetext{
${ }^{4}$ The debate as to how to proceed with all the techniques and their costs and benefits is a long one. The interested reader is referred to Perron and Vogelsang (1992), Lumsdaine, and Papell (1997), Ben-David, Lumsdaine, and Papell (2003), Enders (2004), Shrestha and Chowdhury (2005), Glynn, Nelson and Reetu (2007) for a quick, but non-exhaustive review.

${ }^{5}$ We also conduct the Genc and Arzaghi (2011) test to specifically detect any structural break in the slope of the remittance data. We find no such break, which confirms our findings below. The results are available from the authors upon request.
} 
change in the remittances in MENA. That is because, as articulated before (and also in the literature), the remittance sender countries (largely those in the Gulf) had a policy change around 1990’s from hiring non-GCC Arabs to South Asians. That is why; we should expect a permanent shift in the level of data.

We also observe that all break dates, irrespective of the version of the test employed, are statistically significant. Therefore; we do not make use of other tests with less possibility of structural breaks such as ADF or ZA. ${ }^{6}$ And given the larger absolute value of the "Min t" is obtained from innovational CMR tests, one can say that IO type break is more suitable in explaining the nature of the time series investigated here for both remittance inflows and outflows. This means that break in these variables is more likely to gradually occur over time rather than to abruptly change from the pre-shock mean.

The optimal IO break dates in remittance inflows are 1976 and 2001. The optimal IO break dates in remittance outflows are 1986 and 2005. That points to a claim in the literature that the GCC policy shift actually started much earlier than 1990s (Choucri 1986; Birks, Seccombe and Sinclair 1988; and Kapiszewski 2004). The initial break in these data may also be related to the possible impact of oil embargo in early to mid-1970s, which probably resulted in a lag in the hiring of foreign workers by the GCC countries, and thus their eventual delay in remittance outflows. The latter break dates of 2001 and 2005 are also turmoil years in the larger MENA region with political and military activities.

\section{Conclusions}

In this paper, we take the case of labor importing and exporting countries in MENA with likely economic (as well as social) implications via the labor markets represented by the

\footnotetext{
${ }^{6}$ Results are available from authors upon request.
} 
remittances. Remittances play an important role in alleviating unemployment in certain MENA countries. For many years, local governments in these countries shifted the problem of unemployment, especially for the youth, to labor importing ones. As the labor importing countries, most importantly the GCC countries, also needed the support of foreign labor to man the large economies thanks to the natural resource windfall, the scheme was considered win-win for both sides.

Nevertheless, our econometric analysis shows that there was a change of course in the GCC employment practices, as implied by shocks in the remittance data. In other words, we find that there was an indication of break in the flow of remittances from labor importing countries toward the exporting ones in 1990s when GCC turned to the Asian labor market.

Although we do not directly address the issue of employment policies of the labor exporting countries, we guardedly conjecture that when the wind changed the direction after the 1990s, labor exporting countries were caught off guard. Since they had neglected the aforementioned problems their solutions became more intractable. The stress piled up on their citizens and governments. Eventually, the situation came to a full blown social explosion in 2010, toppling the long running dynasties in some countries. But then again, this claim could be the subject of another paper. Future work can be based on individual data a la Sayan and TekinKoru (2005), Sayan (2006), and Durdu and Sayan (2008). 


\section{References}

Adams, R. “The Determinants of International Remittances in Developing Countries.” World Development 37(1), (2009): 93 - 103.

Baum, C. F. “Stata: The Language of Choice for Time Series Analysis?” The Stata Journal, (2005): 5, 1, 46-63.

Ben-David, D., R. Lumsdaine, and D.H. Papell. "Unit Root, Postwar Slowdowns and Long-Run Growth: Evidence from Two Structural Breaks.” Empirical Economics, (2003): 28(2), 303-319.

Birks, J.S., I. J. Seccombe, and C. A. Sinclair. "Labour Migration in the Arab Gulf States: Patterns, Trends and Prospects.” International Migration, (1988): 26, 3: 267 - 286.

Choucri, N. "Asians in the Arab World: Labor Migration and Public Policy." Middle Eastern Studies, (1986): 22(2), 252-273.

Clemente, J., A. Montanes, and M. Reyes. "Testing for a Unit Root in Variables with a Double Change in the Mean.” Economics Letters, (1998): 59(2), 175-182.

Durdu, C. B., and S. Sayan. "Emerging Market Business Cycles with Remittance Fluctuations," SSRN, (2008): (September 9).

Enders, W. Applied Econometric Time Series, John Willey and Sons, 2004.

Genc, I. H. and M. Arzaghi "A Confidence Interval Test for the Detection of Structural Breaks.” Journal of the Franklin Institute, (2011): 348, 7 (September), 1615-1626.

Genc, I. H., M. Darayseh and B. AbuAl-Foul. "The Nature of Trends in the Per Capita Real GDP of GCC Countries: Some Evidence and Implications.” The Journal of Developing Areas, (2011): 45, 1, (Fall), 19-33.

Glynn, J., P. Nelson, and V. Reetu. "Unit Root Tests and Structural Breaks: A Survey with Applications.” Revista De Metodos Cuntitativos para La Econofa La Empresa, (2007): 3, 63-79.

Kapiszewski, A.“Arab Labour Migration to the GCC States.” Arab Migration in a Globalized World, (2004). Conference organized by International Organization for Migration in Geneva, Switzerland, in 2003.

Khadria, B. “India: Skilled Migration to Developed Countries, Labour Migration to the Gulf.” In Migration and Development: Perspectives from the South. Edited by S. Castles and R. Delgado Wise, 79 - 112. Geneva: International Organization for Migration, 2008.

Lumsdaine, R. and D. H. Papell "Multiple Trend Breaks and the Unit-Root Hypothesis.” Review of Economics and Statistics, (1997): 79, 212-218.

Naufal, G. "Labor migration and Remittances in the GCC.” Labor History, (2011): 52, 3, 307 322.

Naufal, G. and I. Genc. Expats and the Labor Force: The Story of the Gulf Cooperation Council Countries, New York, NY: Palgrave Macmillan, 2012.

Perron, P. and T. J. Vogelsang. "Nonstationarity and Level Shifts with an Application to Purchasing Power Parity.” Journal of Business and Economic Statistics, (1992): 10, 301317.

Russell, S. "Politics and Ideology in Migration: Policy Formulation: The Case of Kuwait." International Migration Review, (1989): 23(1), 24 - 47.

Sayan, S. "Business Cycles and Workers Remittances: How Do Migrant Workers Respond to Cyclical Movements of GDP at Home?” Working Paper, International Monetary Fund WP/06/52, (2006): (February). 
Sayan, S., and A. Tekin-Koru. "Cyclical Properties of Workers Remittances: The Cases of Turkey and Mexico Compared.” Working Paper. Bilkent University, 2005.

Shrestha, M. B. and K. Chowdhury. "A Sequential Procedure for Testing Unit Roots in the Presence of Structural Break in Time Series Data: An Application to Quarterly Data of Nepal.” Journal of Applied Econometrics and Quantitative Studies, (2005): 2, 31-46.

World Bank. World Development Indicators Database. Accessed on September 13, 2011. http://data.worldbank.org/data-catalog/world-development-indicators.

Zivot, E. and D. W. K. Andrews. "Further Evidence on the Great Crash, the Oil Price Shock, and the Unit-Root Hypothesis." Journal of Business and Economic Statistics, (1992): 10, 251-270. 
Figure 1: Mean Remittances Flows in MENA 1970 - 2010 (Source: Naufal, 2011)

Mean Remittances Flows in MENA 1970 - 2010

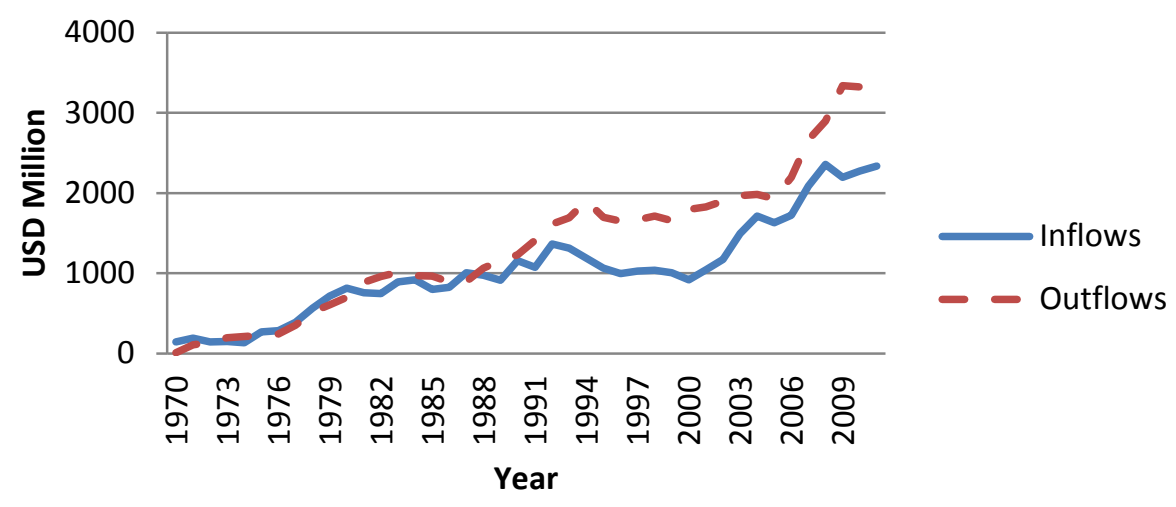




\begin{tabular}{lccc}
\hline & & AO & IO \\
Remittance inflows & B1 & $1980^{*}$ & $1976^{*}$ \\
& B2 & $2004^{*}$ & $2001^{*}$ \\
& Min t & -2.22 & -3.69 \\
Remittance outflows & & & \\
& B1 & $1990^{*}$ & $1986^{*}$ \\
& B2 & $2004^{*}$ & $2005^{*}$ \\
\hline
\end{tabular}

Sample is 1970-2010. Whereas B1 stands for the first break date, B2 represents the second one. The statistically significant breaks at $5 \%$ are identified with an appended asterisk. The "Min t" signifies the lowest $\mathrm{t}$ value obtained from the procedure. The $5 \%$ critical value is -5.49 for the "Min t." 